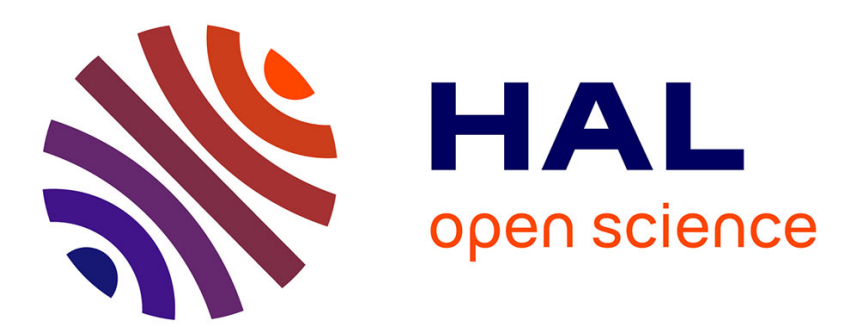

\title{
The PCPDTBT Family: Correlations between Chemical Structure, Polymorphism, and Device Performance
}

\author{
G. Schulz, F. S. U. Fischer, D. Trefz, A. Melnyk, A. Hamidi-Sakr, M. \\ Brinkmann, D. Andrienko, S. Ludwigs
}

\section{- To cite this version:}

G. Schulz, F. S. U. Fischer, D. Trefz, A. Melnyk, A. Hamidi-Sakr, et al.. The PCPDTBT Family: Correlations between Chemical Structure, Polymorphism, and Device Performance. Macromolecules, 2017, 50 (4), pp.1402-1414. 10.1021/acs.macromol.6b01698 . hal-02045675

\section{HAL Id: hal-02045675 \\ https://hal.science/hal-02045675}

Submitted on 17 Dec 2021

HAL is a multi-disciplinary open access archive for the deposit and dissemination of scientific research documents, whether they are published or not. The documents may come from teaching and research institutions in France or abroad, or from public or private research centers.
L'archive ouverte pluridisciplinaire HAL, est destinée au dépôt et à la diffusion de documents scientifiques de niveau recherche, publiés ou non, émanant des établissements d'enseignement et de recherche français ou étrangers, des laboratoires publics ou privés. 


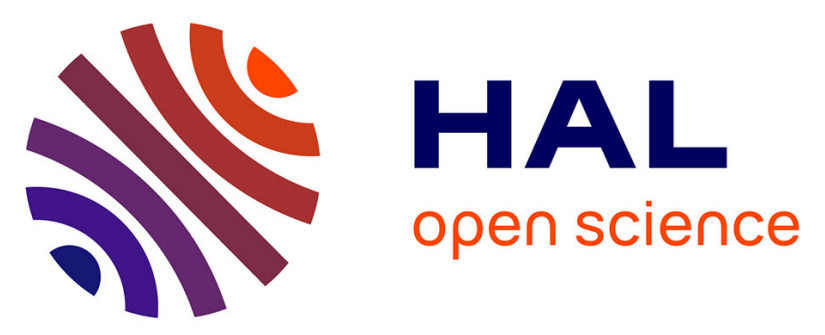

\title{
The PCPDTBT Family: Correlations between Chemical Structure, Polymorphism, and Device Performance
}

\author{
G. Schulz, F. Fischer, D. Trefz, A. Melnyk, A. Hamidi-Sakr, M. Brinkmann, \\ D. Andrienko, S. Ludwigs
}

\section{- To cite this version:}

G. Schulz, F. Fischer, D. Trefz, A. Melnyk, A. Hamidi-Sakr, et al.. The PCPDTBT Family: Correlations between Chemical Structure, Polymorphism, and Device Performance. Macromolecules, American Chemical Society, 2017, 50 (4), pp.1402-1414. hal-02045675

\section{HAL Id: hal-02045675 \\ https://hal.archives-ouvertes.fr/hal-02045675}

Submitted on 17 Dec 2021

HAL is a multi-disciplinary open access archive for the deposit and dissemination of scientific research documents, whether they are published or not. The documents may come from teaching and research institutions in France or abroad, or from public or private research centers.
L'archive ouverte pluridisciplinaire HAL, est destinée au dépôt et à la diffusion de documents scientifiques de niveau recherche, publiés ou non, émanant des établissements d'enseignement et de recherche français ou étrangers, des laboratoires publics ou privés. 


\section{The PCPDTBT family: correlations between chemical structure, polymorphism, and device performance}

G.L. Schulz ${ }^{1}$, F.S.U. Fischer ${ }^{1}$, D. Trefz ${ }^{1}$, A. Melnyk ${ }^{2,3}$, A. Hamidi-Sakr ${ }^{4}$, M. Brinkmann ${ }^{4}$, D. Andrienko ${ }^{2}$, S. Ludwigs ${ }^{1^{*}}$

${ }^{1}$ IPOC-Functional Polymers, University of Stuttgart, Pfaffenwaldring 55, 70569 Stuttgart, Germany

2 Max Planck Institute for Polymer Research, Ackermannweg 10, 55128 Mainz, Germany

3 Graduate School Materials Science in Mainz, Staudinger Weg 9, 55128 Mainz, Germany

${ }^{4}$ Institut Charles Sadron, CNRS - University of Strasbourg, 23 rue du loess, 67034 Strasbourg, France 


\begin{abstract}
We highlight the influence of processing conditions on polymorphism and structure formation on the mesoscale for the family of PCPDTBT polymers with branched alkyl side chains. Direct correlations of morphology to the chemical structure and to transistor device performance are established. We found that up to four different packing motifs could be realized depending on the polymer derivative and the processing conditions: amorphous, -stacked, cross-hatched and dimer-containing polymorphs. While C- and F-PCPDTBT display similar packing behavior organizing in -stacked and dimer-like structures, Si-PCPDTBT gives rise to cross-hatched structures upon simple deposition from solution. The observed differences in chain packing for C-/F-PCPDTBT versus Si-PCPDTBT are related to differences in backbone conformations and aggregation behavior in solution. The effect of polymorphism on charge transport is probed using field-effect transistors, in which both -stacked and cross-hatched polymer chain arrangements yield the highest hole mobilities. Structural and mobility simulations rationalize our experimental findings by relating mobility to distributions of electronic coupling elements between the chains.
\end{abstract}

\title{
1. Introduction
}

The study of the morphology of conjugated polymers has been an active area of research for several decades due to its well-established role in influencing their many opto-electronic properties such as light absorption and charge transport. Regioregular poly(3-hexylthiophene) (P3HT), for example, is a semicrystalline polymer, which has been shown to demonstrate various packing motifs, depending on the deposition conditions, from amorphous to highly ordered stacked arrangements. P3HT polymer chains crystallize in various orientations with respect to the substrate, from face-on to edge-on to standing chains. ${ }^{1}$ Pioneering work in this field was done by Sirringhaus and coworkers, ${ }^{2}$ who investigated the effect of different $\mathrm{P} 3 \mathrm{HT}$ chain orientations on the transistor properties. In edge-on orientation, the field effect mobility is more than 100 times higher than for chains in face-on orientation, which is attributed to excellent charge transport along the chain axis and in the -stacking direction. 3,4 In addition, it was found that solvent vapor annealing could be used to precisely control the crystallization of $\mathrm{P} 3 \mathrm{HT}{ }^{5}$ Charge transport in anisotropic thin films was preferred along the polymer chains over transport in the stacking direction. ${ }^{6}$ Another conjugated polymer that has also been given much attention is poly(9,9-dioctylfluorene) (PFO). ${ }^{7}$ PFO has two reported polymer conformations: and . The -type conformation prevails in PFO thin films exposed to vapors of good solvents, e.g., toluene. Whereas the chain conformation is reported to crystallize in a dimer-containing orthorhombic structure of high symmetry (Pnb21) and to have a less planar backbone than the conformation. 8,9 
Over the years a new class of donor-acceptor (D-A) conjugated copolymers has been developed. In comparison to P3HT and PFO, fewer studies have been performed on the precise packing motifs of these, more advanced, materials.

D-A copolymers are structurally more complex than homopolymers like P3HT and PFO, since they consist of electron rich and electron poor -conjugated building blocks. A typical example of a D-A copolymer

poly[N,N'-bis(2-octyldodecyl)-1,4,5,8-naphthalene-dicarboximide-2,6-diyl]-alt-5,5'-(2,2'-bithiophe ne) (P(NDI2OD-T2)). This low bandgap copolymer has demonstrated impressive optoelectronic properties and has found application in organic field-effect transistors (OFETs) ${ }^{10}$ and organic solar cells ${ }^{11}$ as an n-type semiconductor. Due to the alternating nature of the chemical structure, new packing motifs in comparison to homopolymers, such as segregated and mixed stacking of the donor and acceptor blocks are possible. Two polymorphs of the semicrystalline P(NDI2OD-T2) (known as form I and form II) have been induced in thin films by applying different temperature annealing protocols. ${ }^{12,13}$ Another example of a D-A polymer is the p-type semiconductor poly[2,6-(4,4-bis-(2-ethylhexyl)-4H-cyclopenta[2,1-b;3,4-b']dithiophene)-alt-4,7(2,1,3-benzothiadi azole)] (C-PCPDTBT), which consists of alternating cyclopentadithiophene (CPDT, donor) and benzothiadiazole (BT, acceptor) units (for chemical structure see Scheme 1). C-PCPDTBT was introduced in 2006 by Brabec and coworkers, in an attempt to reduce the bandgap and thus to increase efficiency of a bulk heterojunction solar cell. Indeed, promising power conversion efficiencies (PCEs) up to $3.16 \%$ were demonstrated. ${ }^{14}$ In the following year, Peet and Bazan reported that solvent additives instead of thermal annealing, can lead to PCEs up to $5.5 \%$ for C-PCPDTBT:PC ${ }_{71}$ BM blends. ${ }^{15}$ Further studies indicated that the presence of solvent additive 1,8-diiodooctane (DIO) could improve blend morphology and interchain coupling as a result of enhanced stacking. ${ }^{16,17}$ Later, an edge-on orientation of the C-PCPDTBT polymer chains could be identified using grazing incident X-Ray diffraction techniques (GIXRD) by Nelson, ${ }^{17}$ Bazan, ${ }^{18,19}$ and Russell and coworkers. 20

Considering the promising nature of C-PCPDTBT, structural modifications on the polymer backbone have also been investigated over the last decade. In 2012, Neher ${ }^{21}$ and Jen ${ }^{22}$ both reported on a fluorinated PCPDTBT derivative by replacing one of the hydrogen atoms on the benzothiadiazole ring with a fluorine atom, yielding a regiorandom copolymer: poly[2,6-(4,4-bis-(2-ethylhexyl)-4H-cyclopenta[2,1-b;3,4-b']dithiophene)-alt-4,7-(5-fluoro-2,1,3-be 
nzothiadiazole)] (F-PCPDTBT). PCEs up to $6.6 \%{ }^{23}$ were reported for F-PCPDTBT:PC $71^{B M}$ blends as well as hole mobilities of $10^{-2} \mathrm{~cm}^{2} / \mathrm{Vs}$ in organic field-effect transistors (OFETs). ${ }^{24}$ Several years earlier, in 2008, Yang had described another low band gap polymer in which the bridging carbon atom in the cyclopentadithiophene building block was replaced with a silicon atom: poly[(4,4'-bis(2-ethylhexyl)dithiene-[3,2-b:2',3'-d]silole)-alt-4,7-(2,1,3-benzothiadiazole)] (Si-PCPDTBT). ${ }^{25}$ For the Si containing derivative, PCEs of $5.1 \%$ were obtained as well as hole mobilities up to $10^{-2} \mathrm{~cm}^{2} \mathrm{~V}^{-1} \mathrm{~s}^{-1}$ were measured in OFETs. ${ }^{26}$ Further investigations of Si-PCPDTBT were carried out by Neher and coworkers who implemented multiple fullerene derivatives with Si-PCPDTBT to study the charge transfer state splitting in solar cells. ${ }^{27}$

The differences in charge transport and photovoltaic properties of these three structurally similar low band gap polymers are often rationalized by the strength of their pi-pi stacking interactions. The arguments and packing motif used to support these claims are analogous to those applied to the P3HT semicrystalline morphology. For Si- and C-PCPDTBT, an edge-on morphology is proposed and the relative crystallinity of the two are compared using GIXRD techniques. The silicon containing derivative is more crystalline than C-PCPDTBT and has displayed stacking distances as low as 3.48 ^⿱ versus 3.6-3.8 ^ for C-PCPDTBT. $20,28,29$ Such close packing of the polymer backbone is attributed to the longer Si-C bond versus the $\mathrm{C}-\mathrm{C}$ bond attaching the solubilizing branched alkyl chain to the aromatic units for Si- and C-PCPDTBT, respectively. In the case of F-PCPDTBT versus C-PCPDTBT, -1488172410 the stronger interactions of the fluorinated derivative were attributed to intra or intermolecular $\mathrm{F}-\mathrm{F}$ or $\mathrm{H}-\mathrm{F}$ interactions. $-1488172410^{22}-1488172410$

As a part of our own investigations on the family of PCPDTBT polymers, we have examined the behavior of C-PCPDTBT in solution ${ }^{30}$ and the thin film morphology 31,32 as well as compared the structure and polymorphism of C- versus F-PCPDTBT. ${ }^{33}$ In this report we complete the series with inclusion of the silicon bridged analogue of PCPDTBT which shows yet another polymorph.

In what follows, we describe the processing techniques used to obtain various polymorphs as well as their characteristic traits, starting with C-PCPDTBT, followed by F-PCPDTBT and finally Si-PCPDTBT. This includes structural characterization and measurements of charge carrier mobilities of all polymers in different polymorphs under identical conditions. The experimental results are supported by theoretical calculations performed for the predicted crystalline packing motifs. To this end, we use molecular dynamics simulations to simulate atomistic morphologies of 
large supercells and evaluate charge transfer rates using polarizable force-fields and first principles methods. Kinetic Monte Carlo (KMC) simulations are then used to solve the Master equation for charge dynamics. Finally, we evaluate charge mobility from the KMC trajectories. Simulation results on structures and mobilities are compared to experimental data allowing us to rationalize the molecular packing and the effect of local and mesoscale ordering on charge carrier mobility.

\subsection{Chemical and physical properties}

Scheme 1 shows the chemical structures and molecular weights of three PCPDTBT-based polymers. The molecular weight measurements were performed using high temperature size exclusion chromatography against polystyrene standards. All three polymers have low molecular weights: number average molecular weights $\left(\mathrm{M}_{\mathrm{n}}\right)$ amount to $14.7,6.7$, and $11.0 \mathrm{~kg} / \mathrm{mol}$ for C-PCPDTBT, F-PCPDTBT, and Si-PCPDTBT, respectively.

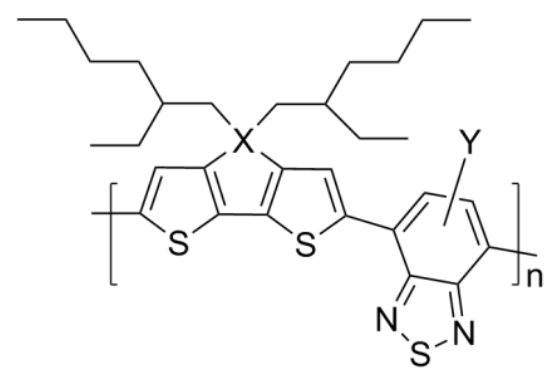

C-PCPDTBT: $X=\mathrm{C}, Y=\mathrm{H}$ Si-PCPDTBT: $X=\mathrm{Si}, Y=\mathrm{H}$ F-PCPDTBT: $X=C, Y=F$

\begin{tabular}{|c|c|c|c|}
\hline & C-PCPDTBT & F-PCPDTBT & Si-PCPDTBT \\
\hline $\mathrm{M}_{\mathrm{w}}(\mathrm{kg} / \mathrm{mol})$ & 26.7 & 10.8 & 32.3 \\
\hline $\mathrm{M}_{\mathrm{n}}(\mathrm{kg} / \mathrm{mol})$ & 14.7 & 6.7 & 11.0 \\
\hline PDI & 1.8 & 1.6 & 2.9 \\
\hline
\end{tabular}

Scheme 1. Chemical structure and molecular weight of the three PCPDTBT-based polymers described in this study.

2.2 Morphology and charge transport simulations 
We start by rationalizing the differences in hole mobilities exhibited by the three PCPDTBT derivatives:Si- and F-PCPDTBT have hole mobilities up to $10^{-2} \mathrm{~cm}^{2} / \mathrm{Vs}$, whereas the mobility of C-PCPDTBT is approximately one order of magnitude lower at $10^{-3} \mathrm{~cm}^{2} / \mathrm{Vs}$ (see Table S1). $22,25,26,28,29,34,35$ These transistors were obtained from classical deposition conditions reported to yield mainly $\pi$-stacked structures. At this stage it remains unclear whether the change in the electronic structure, local molecular packing, or mesoscale ordering of chains in the film is responsible for the change in the hole mobility.

To rule out contributions due to the change in the electronic structure, we first analyze electronic coupling elements (transfer integrals) between two tetramers (four donor-acceptor pairs) in a -stacked arrangement. These couplings are plotted as a function of the relative shift between two backbones in Figure 1. The separation between two chains is fixed to, corresponds to ageometry of a dimer in a stack morphology with a minimal side-chain overlap, i.e. when the acceptor (BT) units are on top of each other, while the donor (CPDT) units are spatially separated due to backbone bending, as shown in Figure $7(a, b)$. In this model system, branched ethyl-hexyl side-chains are replaced with hydrogens in order to reduce computational costs.

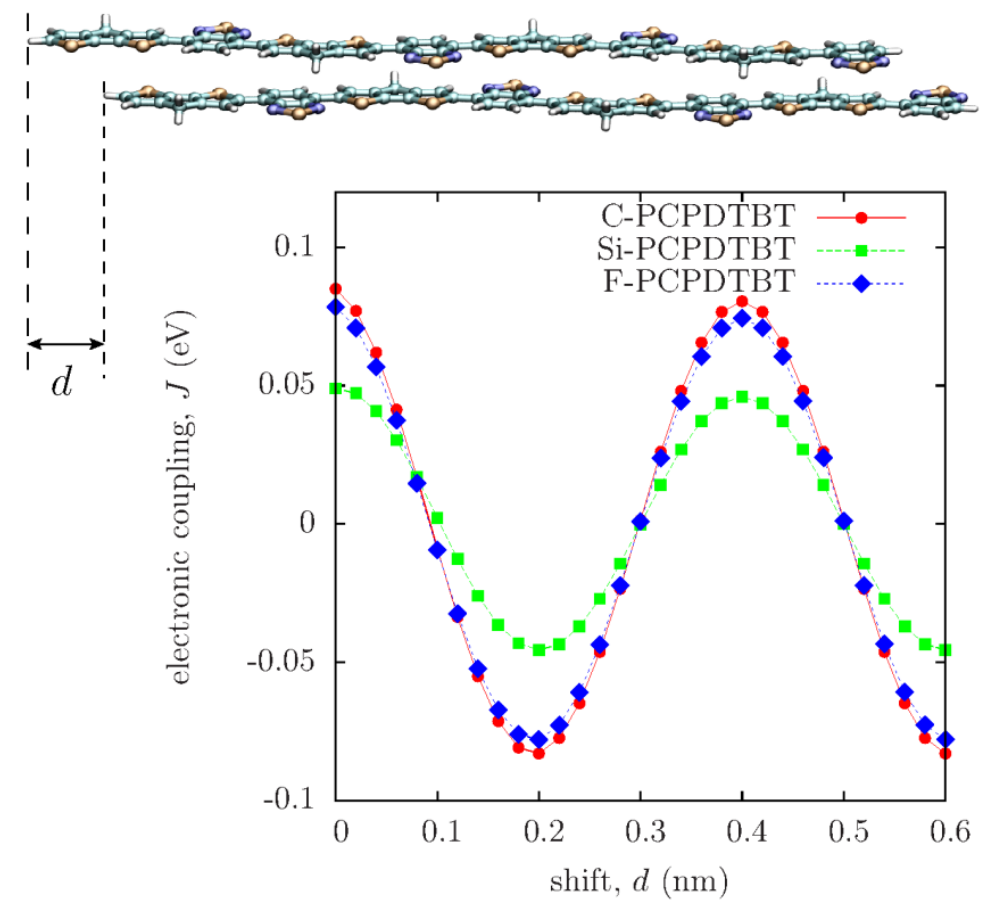

Figure 1. Electronic coupling element between two backbones (tetramers with side chains substituted by hydrogens) versus the backbone-backbone shift. Backbones are parallel to each other and constrained to a fixed separation of. Electronic couplings are evaluated using the projection method ${ }^{36}$, B3LYP density functional, and $6-31 \mathrm{~g}$ basis set $^{37}$. The monomer length is similar for all three derivatives and set to $11.8 \AA$. 
Evidently, all three polymers have a similar dependence of the electronic coupling on the relative shift . Si-PCPDTBT has the lowest coupling for this given dimer geometry (see SI, Section C for details). This observation is in a clear contradiction to the experimental observations, with Si-PCPDTBT having the highest OFET mobility. We can therefore conclude that the change in the electronic structure alone cannot be responsible for the change in charge mobility. Hence, different polymers havedifferent mesoscale ordering of backbones.

To further assess the influence of chain packing on charge transport, we have performed molecular dynamics simulations of large supercells of 128 tetramers with ethyl-hexyl side-chains. The simulation box of 4 lamellae with 32 chains per lamella has been equilibrated at $300 \mathrm{~K}$ and ambient pressure using Berendsen thermostat and barostat [36(??)]. Typical simulated morphologies are shown in Figures $3 a$ (unit cell) and $3 b$ (super cell). The corresponding unit cell parameters are similar for C- and F-PCPDTBT:-stacking distance is and inter-lamellar spacing is . In case of Si-PCPDTBT the corresponding values are and. We then used 10 snapshots of the 1 ns production run in order to perform averages of the distribution of electronic coupling elements, site energies, and mobilities.

Electronic coupling elements were evaluated using the projection method ${ }^{36}$ with diabatic states constructed from HOMO energy levels of hydrogen-saturated tetramers. With the electronic couplings at hand we have evaluated intermolecular charge transfer rates using the high-temperature limit of non-adiabatic charge transfer theory ${ }^{38}$.

$$
k_{A \rightarrow B}=\frac{2 \pi}{\hbar} \frac{J_{A B}^{2}}{\sqrt{4 \pi \lambda k_{\mathrm{B}} T}} \exp \left[-\frac{\left(\Delta U_{A B}-\lambda\right)^{2}}{4 \lambda k_{\mathrm{B}} T}\right]
$$

Here $\lambda=0.1 \mathrm{eV}$ is the reorganization energy, $J_{A B}$ the electronic coupling, and $\Delta U_{A B}=U_{A}-U_{B}$ the driving force. All these parameters were evaluated using a combination of quantum-chemical methods and classical polarizable force-fields. ${ }^{39,40}$

The rates and centers of mass of molecules were used to parameterize the master equation which was solved using the kinetic Monte Carlo (KMC) algorithm. ${ }^{41}$ The intermolecular charge-carrier mobility along the direction of the external field was obtained from the charge trajectory as 


$$
\mu=\frac{\langle\Delta \vec{R} \cdot \vec{E}\rangle}{\Delta t|\vec{E}|^{2}}
$$

where $\Delta R$ is the displacement of charge over a simulation time $\Delta t$. The electric field was along the $\pi$-stacking axis. The results of simulations are summarized in Table 1 . Since we do not take into account energetic disorder and defects, such as grain boundaries and amorphous regions, the calculated mobilities are higher than the experimental ones. The trend is, however, clear: the carbon-bridged polymer has the lowest and the silicon-based PCPDTBT the highest mobility. Hence, we can conclude that the local chain packing favors larger hole mobility in Si-PCPDTBT. This can indeed be confirmed by looking at the distributions of electronic couplings in the simulated morphologies (see Supporting Information, Figure S4): Si-PCPDTBT has the largest average coupling. Better registry of backbones in Si-PCPDTBT could be attributed to longer Si-C bonds and softer attachment of alkyl side chains due to a larger, as compared to carbon, $\mathrm{Si}$ atom. ${ }^{42}$ Indeed, the side chains of Si-PCPDTBT are on average further away from the backbone, leading to larger interlamellar separations and, correspondingly, smaller distances. Energetic disorder in the lamellar arrangements of all three polymers is rather large, in part due to conformational disorder of side chains. If accounted for, it leads to a three order of magnitude decrease of mobility (at low charge carrier densities) for all three polymers.

Even though the local ordering already favors transport in Si-PCPDTBT as compared to other derivatives, the difference in simulated mobilities is still smaller than measured in OFETs. This indicates that large-scale molecular arrangement further favours transport in Si-PCPDTBT.

Table 1. Summary of transistor characteristics of the -stacked polymers. Simulated mobility $\left(\mu_{\text {sim }}\right)$ values are given without taking into account energetic disorder (i.e. assuming high charge carrier densities in OFETs). Averaging is based on 1280 points for each system, the largest error is less than $10^{-3} \mathrm{~cm}^{2} / \mathrm{V}$.s. With energetic disorder, the simulated zero-field mobility is than $10^{-6} \mathrm{~cm}^{2} / \mathrm{V} \cdot \mathrm{s}$.

\begin{tabular}{|l|l|}
\hline$\pi$-stacked structures & $\mu_{\text {sim }}\left(\mathrm{cm}^{2} / \mathrm{V} \mathrm{s}\right)$ \\
\hline C-PCPDTBT & $7.8 \times 10^{-2}$ \\
\hline F-PCPDTBT & $10.5 \times 10^{-2}$ \\
\hline Si-PCPDTBT & $18.6 \times 10^{-2}$ \\
\hline
\end{tabular}




\subsection{Aggregation in solution}

As start of our experimental investigations, we first compare the aggregation behavior of all PCPDTBT derivatives using temperature dependent UV-vis absorption spectroscopy (Figure 2). Through the appropriate choice of solvent and a wide temperature window, one can in an ideal case, observe a transition from the fully dissolved (high temperature) to the highly aggregated state (low temperature). Before going into detail about the absorption spectra of each polymer, it should also be noted that for all PCPDTBT polymers, the high energy band seen at around $400 \mathrm{~nm}$ and the low energy band at about $700 \mathrm{~nm}$ are assigned to a and charge transfer transition, respectively. ${ }^{30}$ Figure $2 a$ displays the measured absorption profiles for C-PCPDTBT in CB from -15 (blue) to $100^{\circ} \mathrm{C}$ (red). From high temperature down to room temperature, the maximum absorption wavelength was found to be at $710 \mathrm{~nm}$ and the spectral shape can be described as rather broad with a slight shoulder at high energy $(\sim 660 \mathrm{~nm})$. Cooling towards $-15^{\circ} \mathrm{C}$ (spectrum shown in blue), a $15 \mathrm{~nm}$ red-shift of the absorption maximum up to $725 \mathrm{~nm}$ is observed. In a recent publication we have described the aggregation behavior of C-PCPDTBT in 2-methyltetrahydrofuran (m-THF) between $-93^{\circ} \mathrm{C}$ and $67^{\circ} \mathrm{C}$ using absorption and photoluminescence spectroscopy. These experiments in combination with an evaluation via Franck Condon analysis revealed an isosbestic point and thus two polymer conformations: a disordered random coil and an aggregated conformer with planarized chains. ${ }^{30}$ At low temperature it was deviated that the aggregated phase of C-PCPDTBT consisted of long-range stacked polymer chains. Both in $\mathrm{m}$-THF and in THF PCPDTBT is slightly more aggregated at room temperature, Figure S1.

For the F-PCPDTBT polymer, the temperature dependent absorption spectra are displayed in Figure $2 \mathrm{~b}$. The spectrum measured at $100^{\circ} \mathrm{C}$ shows a maximum absorption at $690 \mathrm{~nm}$, with a hint of a shoulder at $660 \mathrm{~nm}$. At room temperature, the maximum is shifted to $710 \mathrm{~nm}$. Upon further cooling to $-15^{\circ} \mathrm{C}$, is at $720 \mathrm{~nm}$ and a shoulder at $780 \mathrm{~nm}$ becomes clearly visible.

Si-PCPDTBT displays analogous trends in its absorption behavior as the other two polymers, but with much stronger aggregation tendency. At $100^{\circ} \mathrm{C}$ (Figure 2c, red spectrum), the maximum absorption is at $655 \mathrm{~nm}$, whereas at $20^{\circ} \mathrm{C}$ and lower temperatures two distinct maxima at 655 and $750 \mathrm{~nm}$ become visible. 

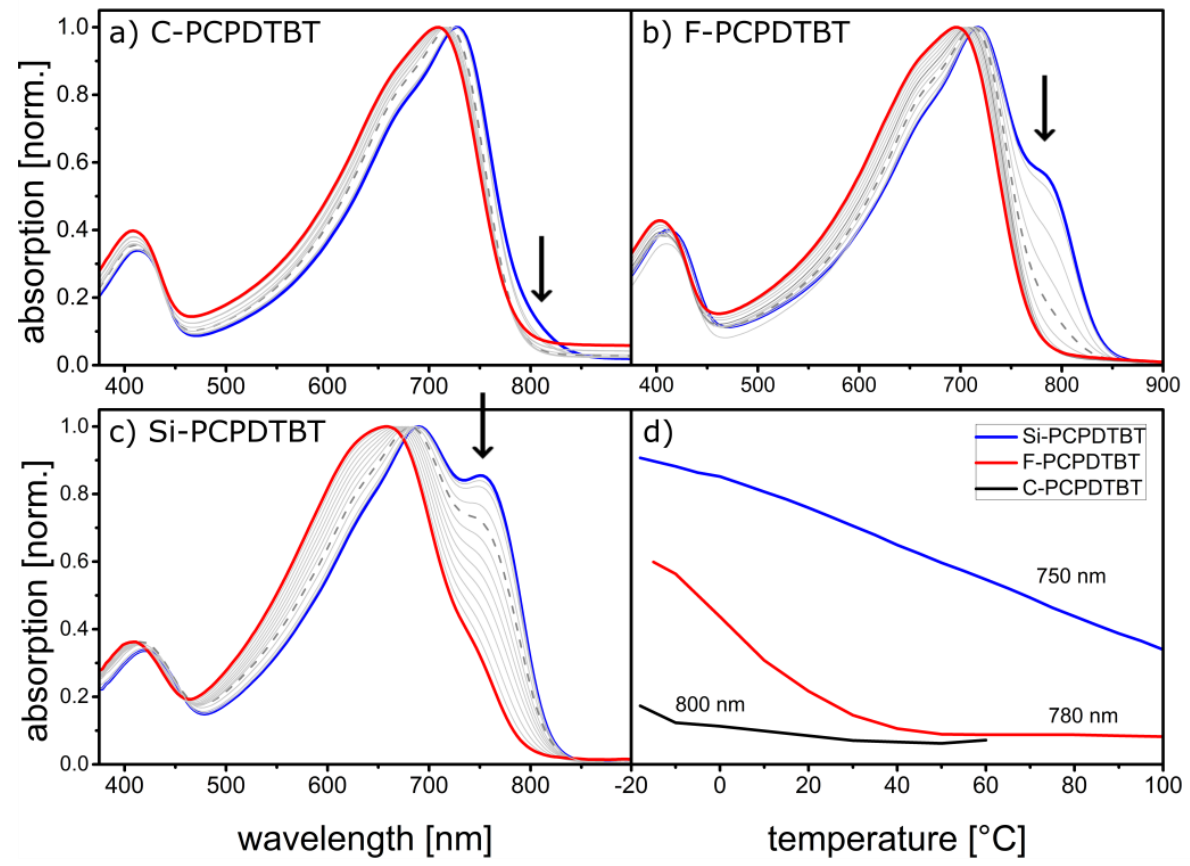

Figure 2. Temperature dependent absorption spectra of polymer solutions in $C B(1 \mathrm{mg} / \mathrm{mL})$ a) C-PCPDTBT, b) F-PCPDTBT, and c) Si-PCPDTBT, measured in the temperature range between $100^{\circ} \mathrm{C}$ (red) and $-15^{\circ} \mathrm{C}$ (blue) with $10^{\circ} \mathrm{C}$ temperature steps shown in grey. Spectra measured at RT shown as dashed line. d) Change in intensity of the shoulder at long wavelengths $(750-800 \mathrm{~nm})$ as a function of temperature for the three PCPDTBT polymers.

In Figure 2d, the decay of the aggregated species in solution is depicted by plotting the absorption intensity evolution of the low energy peak $(750-800 \mathrm{~nm})$ as a function of temperature for all three polymers. For C-PCPDTBT, no clear shoulder can be observed indicating that very little aggregation occurs in chlorobenzene solution (refer to Figure 2a). For F-PCPDTBT, the shoulder at $780 \mathrm{~nm}$ is less intense than for Si-PCPDTBT and decreases steadily in intensity from $-15^{\circ} \mathrm{C}$ to $40^{\circ} \mathrm{C}$. The silicon containing polymer however displays a shoulder at $750 \mathrm{~nm}$ over the entire temperature range. The results clearly indicate the tendency to undergo aggregation increases in the series: C-PCPDTBT, F-PCPDTBT, Si-PCPDTBT. Depending on the solvent in which the polymer is dissolved, the aggregates can be present in solution at room temperature, for example like the case of Si-PCPDTBT in CB or C-PCPDTBT in THF (refer to Figure S1) but not for C-PCPDTBT in CB (see Figure 2). Additionally, we further observed a significant decrease in polymer solubility from C-PCPDTBT to F-PCPDTBT to Si-PCPDTBT. We note that materials with low solubility can in extreme cases, limit the processing and characterization techniques that can be applied to study such conjugated polymer systems. Later during the spincoating process aggregation in solution becomes important because it influences structure formation if pre-aggregated species are deposited or forming during the drying process. 


\subsection{C- and F-PCPDTBT}

The film morphology of a conjugated polymer is influenced by a variety of factors such as chain rigidity, molecular weight, length and density of alkyl side chains, solubility, aggregation and crystallinity, etc. It has been found that subtle changes in chemical structure, e.g. the inclusion of a fluorine atom on a benzothiadiazole unit (as is the case for F-PCPDTBT versus C-PCPDTBT) or variations of the solubilizing side chains can result in significant changes in polymer properties. $^{21,22,34}$ The protocol and the solvent used to fabricate the thin films plays an equally important role in determining the final morphology, as shown for example in depth for $\mathrm{P} 3 \mathrm{HT}$ as

model system. ${ }^{1,48}$ Finally, after film formation, further modification of the morphology can be achieved by thermal or solvent annealing. In the upcoming section it will be shown how chemical structure, deposition technique, and post-deposition treatment influence polymer film morphology for C- and F-PCPDTBT.

To date, the PCPDTBT polymers have been shown to demonstrate up to three different morphologies: amorphous, -stacked and the more recently reported 'dimer' structure. ${ }^{32,33}$ The latter two packing motifs are depicted in Figure 3 as a point of reference for the reader. Figures $3 a$ and $3 \mathrm{~b}$ depict the polymer chain arrangement of the -stacked polymorph after equilibration using molecular dynamic simulations. The long range -stacked structure of C-PCPDTBT (and its Si-analogue) has been proposed based on the results of GIXRD experiments. It is noteworthy to mention that such -stacked structures typically display an edge-on orientation. 20,28

In addition, both F- and C-PCPDTBT form a semicrystalline arrangement whose crystal structure has been assigned to the Pccn space group which is very similar to that which has been reported for $\alpha$-PFO (Pnb21). ${ }^{33}$ The orthorhombic unit cell contains 4 polymer chains grouped into pairs (dimers, Figure $3 \mathrm{c}$ and $3 \mathrm{~d}$ ). CPDT and BT units are stacked in a segregated manner in the dimers, forming stacked PCPDTBT polymer chains. The alkyl side chains are surrounding the two planar backbones, and insulate the individual dimer units from one another. An important finding that has emerged during the investigations of the dimer crystal structure is that it is thermodynamically more stable than the -stacked polymorph. ${ }^{33}$ 

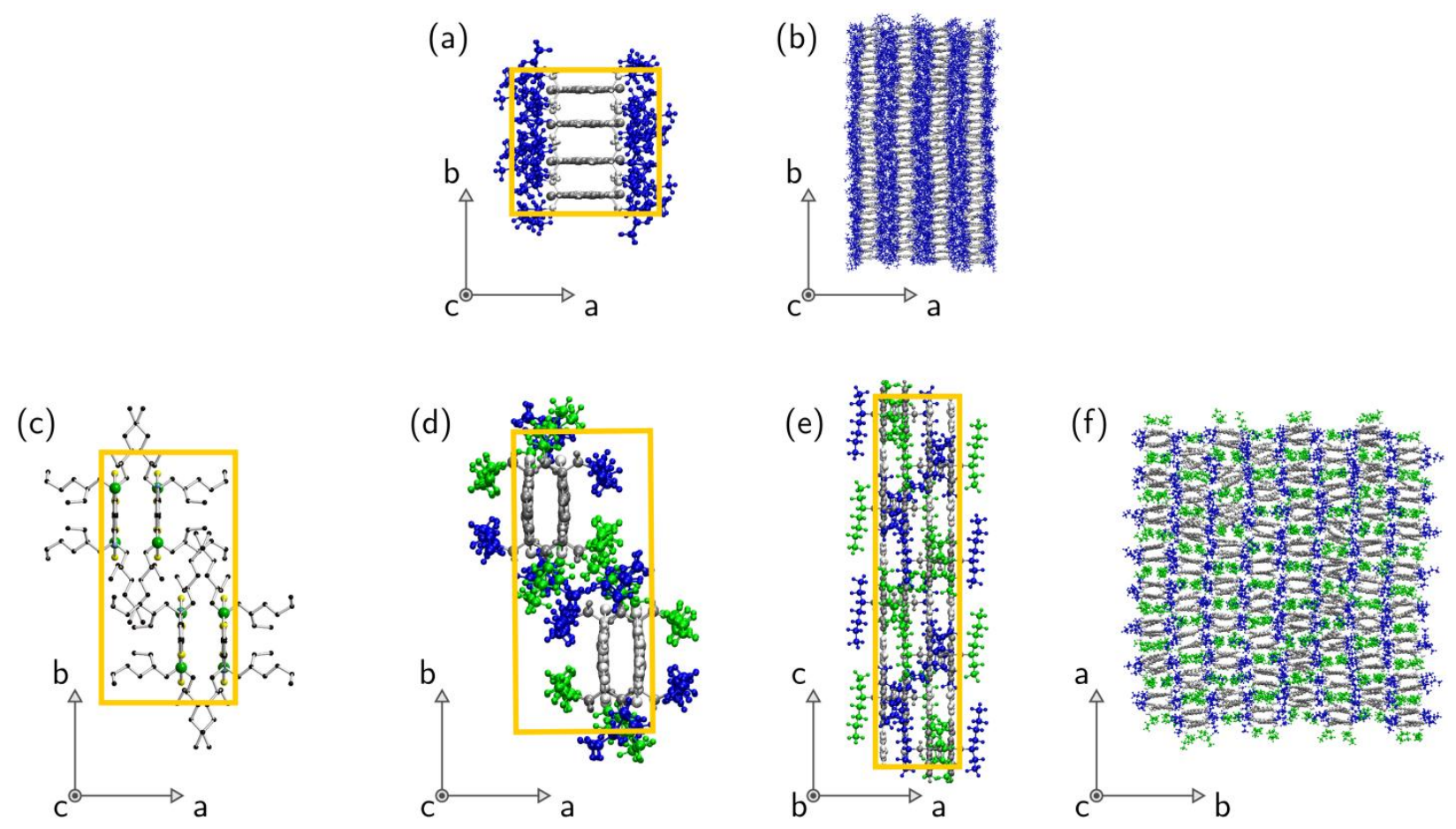

Figure 3. Unit cells illustrating polymorphs of PCPDTBT polymers: (a) -stacked unit cell and (b) supercell, equilibrated using molecular dynamics. Dimer-containing unit cell of F-PCPDTBT: (c) proposed crystal structure from experimental studies, ${ }^{33}(\mathrm{~d}),(\mathrm{e})$, and (f) after equilibration using molecular dynamics simulations. The final unit cell dimensions are given in Table 2. The -stacked polymorph has been observed for all C-, Si-, and F-PCPDTBTs, whereas the dimer-like structure for F-PCPDTBT ${ }^{33}$ and C-PCPDTBT. 32,33

The proposed dimer-like polymer arrangement for C-PCPDTBT and F-PCPDTBT is examined in more detail in References 32,33 . Figure $3 c$ exemplarily shows the projection of the crystal structure of F-PCPDTBT in the plane. It has to be noted that the stacking distance between two chains within a dimer was estimated to be between, no long range stacking is possible in these structures. In order to validate the experimentally predicted unit cell of a dimer structure, we have additionally performed molecular dynamics simulations with this molecular arrangement. Supercells ( unit cells, with four tetramers in each unit cell) were constructed from the proposed unit cells and equilibrated at $300 \mathrm{~K}$ and ambient pressure for $1 \mathrm{~ns}$. All supercells were stable during the entire equilibration run. As an example, the final unit cell and super cell for F-PCPDTBT are shown in Figure 3d, 3e, and 3f. The unit cell dimensions, summarized in Table 2, are in good agreement with experiment. Note that even though our simulations support experimental findings only indirectly (since free energy calculations of large supercells are computationally prohibitive), 
a combination of molecular dynamics simulations and TEM/ED allows the identification of detailed molecular arrangements in unit cells, accounting for the excluded volume of branched side chains.

\begin{tabular}{|c|c|c|c|}
\hline & (along the backbone, $\mathrm{nm}$ ) & $(\mathrm{nm})$ & $(\mathrm{nm})$ \\
\hline C-PCPDTBT (simulated) & 2.46 & 2.08 & 1.25 \\
\hline C-PCPDTBT (experiment ${ }^{33}$ ) & 2.36 & 1.93 & 1.24 \\
\hline F-PCPDTBT (simulated) & 2.40 & 2.20 & 1.17 \\
\hline F-PCPDTBT (experiment ${ }^{33}$ ) & 2.32 & 2.06 & 1.10 \\
\hline
\end{tabular}

\subsubsection{Preparation Conditions - Structural Analysis}

Next we present the preparation techniques which can be used to obtain the various polymer morphologies as well as their characteristic traits. The thin film morphology of C-PCPDTBT spincoated from two different solvents: $\mathrm{CHCl}_{3}$ and $\mathrm{CB} / \mathrm{DIO}$ are shown using atomic force microscopy (AFM) height images in Figure 4a and 4b, respectively. The sample deposited using chloroform displays no characteristic features in the AFM images, $4 \mathrm{a}$, and the corresponding absorption profile is broad and featureless, see Figure $4 \mathrm{~d} .{ }^{31}$ These results as well as the rather fuzzy and weak -stacking reflection in the ED pattern (Fig. S5e) led us to the conclusion that the sample spincoated from chloroform is rather amorphous in nature. In contrast, films deposited from high boiling point mixture of $\mathrm{CB}$ and DIO yielded excellent solar cell performance ${ }^{15}$ and polymer chains have extended stacking interactions as suggested from a rather sharp and intense Scherrer ring at $3.75 \AA ̊$ in the ED pattern (see Figure S6).

Such -stacked aggregates have also been observed for P3HT, and for C-PCPDTBT consist of an edge-on orientation with respect to the substrate. ${ }^{20,28}$ The AFM height image shown below reveals round aggregates on the film surface, approximately $40 \mathrm{~nm}$ in diameter, 4b. A distinct shoulder at $800 \mathrm{~nm}$ can be seen in the absorption spectrum of the thin film spincoated from $\mathrm{CB} / \mathrm{DIO}$ (Figure 4d). In analogy to the peak assignment performed in temperature dependent absorption spectroscopy experiments, ${ }^{30}$ in the thin films spincoated from CB/DIO, we also assign 
the presence of the shoulder at long wavelength, to ordered, -stacked, C-PCPDTBT polymer chains.

DIO as well as other high boiling point solvents (e.g. 1-CN) are needed for C-PCPDTBT to force the polymers in the long-range pi-stacked structure; pre-aggregation in solution seems to play a major role in this context.

\section{C-PCPDTBT}

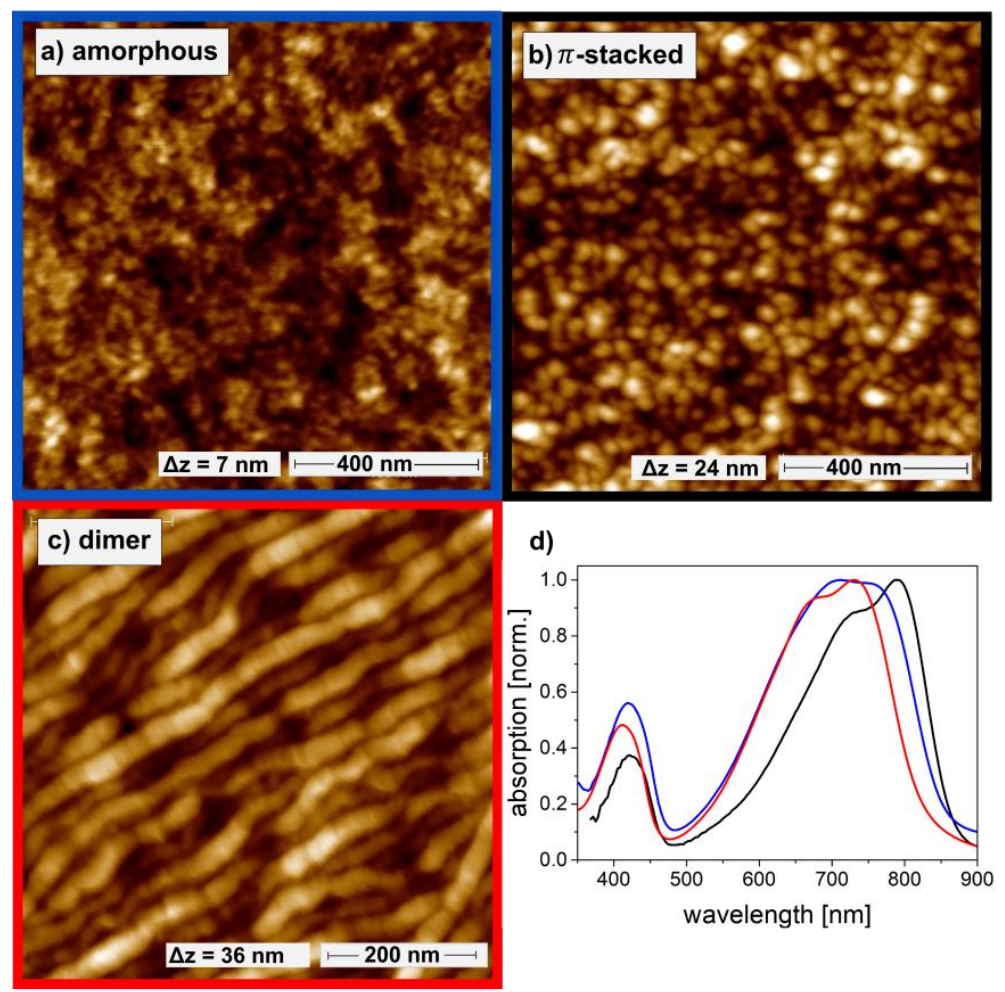

Figure 4. AFM height images (1x1 $\mu \mathrm{m})$ of C-PCPDTBT: a) spincoated from $\mathrm{CHCl}_{3}$ yielding a mainly amorphous film, b) spincoated from $\mathrm{CB} / \mathrm{DIO}$ yielding the pi-stacked structure, and c) spincoated from $\mathrm{CHCl}_{3}$, and exposed to $\mathrm{CS}_{2}$ vapor afterwards yielding the dimer crystal structure. (d) Absorption spectra of thin films: spincoated from $\mathrm{CHCl}_{3}$ : blue, spincoated from $\mathrm{CB} / \mathrm{DIO}$ : black, and after exposure to $\mathrm{CS}_{2}$ vapor: red. For further morphological data on C-PCPDTBT we refer to Figures S5-7.

To access the dimer crystal structure we found that melt crystallization on PTFE films and solvent vapor annealing of spincoated films can be used. 32,33 (compare Figure S7). Using the latter approach with carbon disulfide as solvent vapor homogeneous films are accessible, Figure 4c. Fiber-like structures with a diameter of $40 \mathrm{~nm}$ can be seen on the surface in the AFM height image. The absorption spectra of the solvent annealed film shows a blue-shift of the maximum of about 40 $\mathrm{nm}$ compared to the film spincoated from CB/DIO and a pronounced shoulder at $650 \mathrm{~nm}$. Using 
TEM/ED (Figure 7e $+h$ ) and GIWAXS measurements (Figure S7f), the film exposed to solvent vapor was confirmed to adopt the dimer structure (Figure 3c-f). Figure S7h shows the characteristic traits in the ED pattern for C-PCPDTBT in the dimer arrangement with 110 and 00 4 reflections, displayed at 10.5 and $5.9 \AA$, respectively. ${ }^{33,49}$

Overall, three different polymer morphologies were obtained for the C-PCPDTBT derivatives: amorphous, -stacked and dimer crystal structure.

A similar approach to that used for C-PCPDTBT was applied to samples consisting of F-PCPDTBT. Interestingly no amorphous films were accessible by solution-deposition. Spincoating from a solvent with a high boiling point such as chlorobenzene led to rod-like structures (diameter $=30 \mathrm{~nm}$ ) in the AFM height image shown in Figure 5a. TEM also revealed rod-like structures whereas the ED pattern shows an intense pi-stacking ring at $3.7 \AA$ and a weak ring with a 11.0Å interlayer spacing (see Figure S8). These reflections point indeed at a -stacked structure with a dominant population of edge-on oriented crystals.

The corresponding absorption profile of the same thin film shows a band centered around $750 \mathrm{~nm}$ with an intense shoulder at $790 \mathrm{~nm}$ (Figure 5e). The shoulder observed at $790 \mathrm{~nm}$ is assigned to aggregates in the thin film that are of the same nature as those seen in the $\mathrm{CB}$ solution at $-15^{\circ} \mathrm{C}$ (Figure 2b) which consist of long-range -stacked polymer chains. For the carbon bridged analogue of PCPDTBT, additives with high boiling points such as diiodooctane (b.p. $365^{\circ} \mathrm{C}$ ) were needed to induce the stacking, however for F-PCPDTBT, chlorobenzene (b.p. $132^{\circ} \mathrm{C}$ ) was sufficient since it has a higher tendency to aggregate in solution than C-PCPDTBT.

Again solvent vapor annealing had been shown to lead to the dimer crystal structure, with the only problem that no continuous films could be obtained. ${ }^{33}$ High temperature mechanical rubbing proved to be a good alternative in this polymer, Figure 5 . The existence of the dimer crystal structure is highlighted by the characteristic reflections at $10.5 \AA$ and $5.8 \AA$ in the ED pattern in Figure $5 b .{ }^{33}$ Bright field TEM images as well as AFM images of such films were recorded and can be seen in Figure $5 c$ and $5 d$, respectively. In both the TEM and AFM images, lamellae perpendicular to the rubbing direction can be seen, consistent with polymer chain alignment. The semicrystalline nature of F-PCPDTBT is evidenced in the TEM image which shows alternating light and dark regions, corresponding to amorphous and crystalline domains within the polymer film. Polarized optical absorption spectroscopy was employed to assess the degree of alignment after HT rubbing. Through comparison of the ratio of intensities at the wavelength of maximum absorption, a moderate dichroic ratio of 2.3 was obtained, Figure S2a. Not surprisingly, it was also 
found that the absorption spectrum of the rubbed film is blue shifted compared to the thin film spincoated from chlorobenzene (see Figure 5e), and a new absorption maximum at $695 \mathrm{~nm}$ is observed. Accordingly for F-PCPDTBT, only two polymorphs were obtained: -stacked and dimer. We attribute the absence of the amorphous phase to the higher tendency of F-PCPDTBT to aggregate versus C-PCPDTBT as demonstrated in Figure 2.
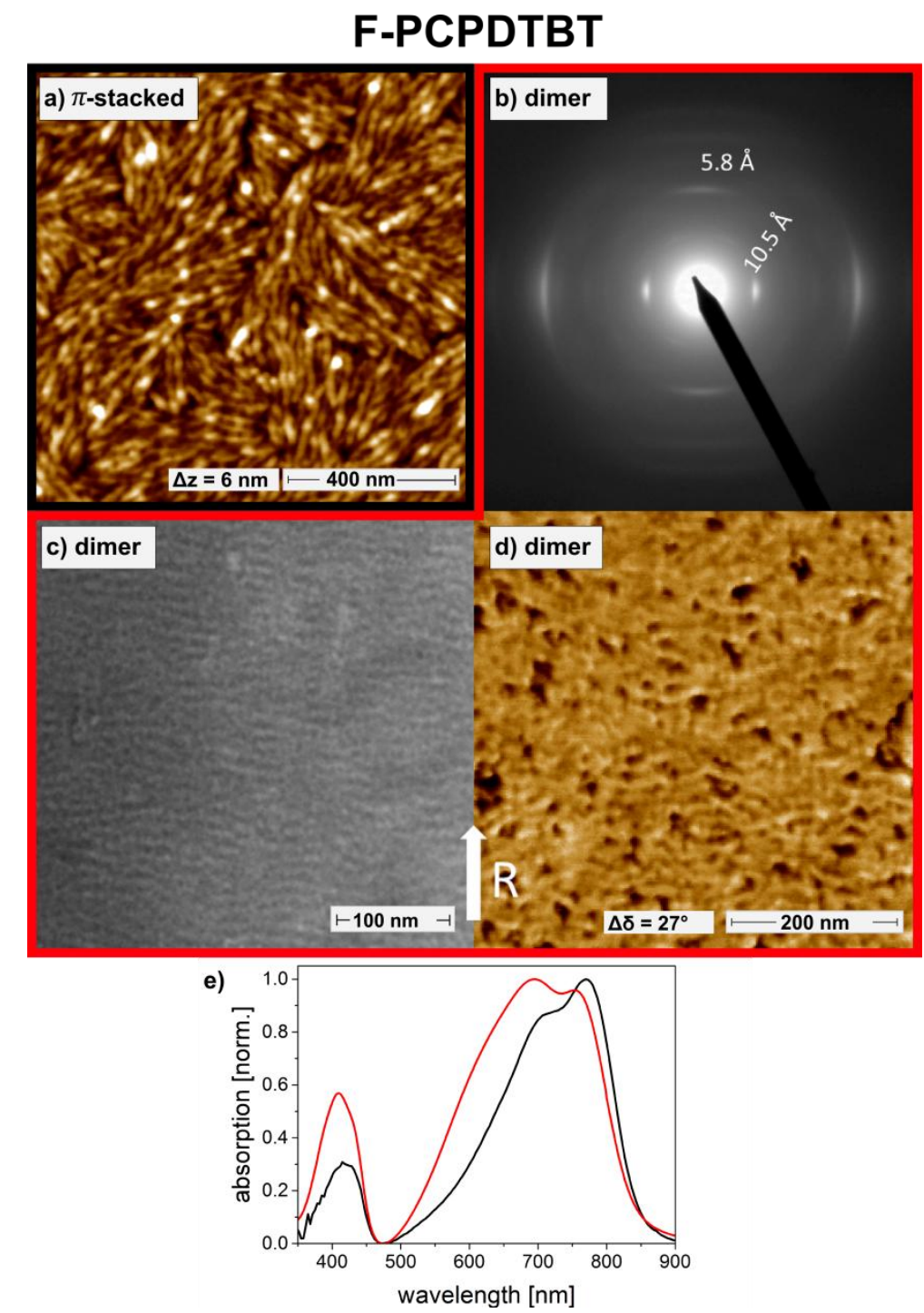

Figure 5. AFM height image of F-PCPDTBT spincoated from CB (a) exhibiting a -stacked morphology. ED pattern (b), HR-TEM image (c), and AFM phase image (d) of a thin film of F-PCPDTBT after HT rubbing at $240^{\circ} \mathrm{C}$. White arrow indicates the rubbing direction. e) Corresponding absorption spectra of the -stacked and dimer-containing structures, black and red lines, respectively. For further morphological data on F-PCPDTBT we refer to Figures S8 + 9 .

\subsubsection{Charge Transport Measurements}


The hole mobilities of the different polymorphs of C- and F-PCPDTBT were evaluated using field-effect transistors in a top-gate bottom-contact geometry. This device architecture was employed since the same polymer interface investigated in AFM is probed during transistor operation. The resulting output and transfer curves can be found in the supporting information (Figures S12 + S13). For C-PCPDTBT we found the following values: the -stacked morphology (prepared from CB/DIO, Figure 4a) gave values around .... with a highest mobility of .... . Films containing the dimer crystal structure (prepared via SVA-CS 2 , Figure $4 \mathrm{~b}$ ) gave average values of around .... The amorphous films (prepared from $\mathrm{CHCl}_{3}$, Figure $4 \mathrm{c}$ ), gave average values of .... The dimer morphology and the amorphous film of C-PCPDTBT yield hole mobility values almost one order of magnitude lower than the samples with long-range stacking. This result indicates that these structures are not well suited for effective transport in FETs. In the case of the dimer structure this is likely due to the large distance between dimer units as a result of the insulating alkyl chains. Although the dimer structure of the PCPDTBT chains is highly crystalline, transport can really only occur along the polymer chains.

In the case of F-PCPDTBT we compared -stacked (prepared from CB, Figure 5a) vs. dimer (prepared via HT-rubbing, Figure 5b-d) and found very similar charge carrier mobilities in the order of $2 \times 10^{-4} \mathrm{~cm}^{2} / \mathrm{Vs}$. In the literature charge carrier mobilities of F-PCPDTBT have been reported to be between $1 \times 10^{-3}$ and $1.4 \times 10^{-2} \mathrm{~cm}^{2} / \mathrm{Vs},{ }^{21,22}$ which is one to two orders of magnitude higher than the values we measured. We attribute this discrepancy to the low molecular weight of our polymer batch, as molecular weight has frequently been shown to be an important factor in determining charge carrier mobilities of conjugated polymers. 50,51

The transistor characteristics of the HT rubbed film were obtained by rubbing in the direction parallel to the transport direction between source and drain contacts. We also performed the same rubbing experiments perpendicular to the transport direction (see Table S2 in the supporting information), which gives a mobility of $6 \times 10^{-5} \mathrm{~cm}^{2} / \mathrm{Vs}$. The observation of anisotropic transport in these dimer structures indicates that charges are transported more efficiently along the conjugated backbones. Intermolecular transport occurs either via a superexchange mechanism, via tunneling over side chains, or through numerous structural defects, since these structures do not provide a direct electronic overlap between molecules. This charge transport anisotropy is in accordance to findings on P3HT and other D-A copolymers. 6,12,48

Overall we conclude that stacking of the PCPDTBT chains best supports charge transport in OFETs for C- and F-PCPDTBT. 


\subsection{Si-PCPDTBT - Structural Analysis \& Charge Transport}

The last polymer in the series is the silicon-bridged cyclopentadithiophene analogue of PCPDTBT. It is also the least soluble material in the series and due to its very high tendency to aggregate in solution, it was not possible to make homogeneous thin films using standard spincoating conditions. We found that films of sufficient quality could be obtained by spincoating from hot solutions of chlorobenzene $\left(80^{\circ} \mathrm{C}\right)$. The AFM phase image of the resulting film is displayed in Figure $6 \mathrm{a}$ and reveals round aggregates approximately $30 \mathrm{~nm}$ in diameter. Surprisingly, the HR-TEM image in Figure $6 \mathrm{~b}$ evidences the formation of cross-hatched structures. Cross-hatched structures have been demonstrated for polypropylenes and poly(paraphenylene benzobisoxazole), ${ }^{52}$ but were only recently reported for Si-PCPDTBT by Takacs and coworkers in very thin films. ${ }^{53}$ The cross-hatched structures consist of alternating layers of polymer chains in which the angle between two chains from adjacent layers was found to be $53.61 .3^{\circ}$. This angle of $53.6^{\circ}$ can be seen in the FFT pattern shown in the upper right hand corner in Figure $6 \mathrm{~b}$ which reveals two clear sets of reflections $53.6^{\circ}$ from one another. Incidentally, the same cross-hatched domains were also observed when aggregates of Si-PCPDTBT formed in solution were cast on a carbon-coated TEM grid, indicating that such aggregates are formed in solution and not upon drying during spincoating (see supplementary information Figure $\mathrm{S} 11 \mathrm{~g}+\mathrm{h}$ ). The periodicity between successive chains in a layer was $17.4 \AA$, in agreement with earlier findings. ${ }^{53}$ The absorption spectrum of the spincoated thin film displays a maximum intensity at $765 \mathrm{~nm}$ (Figure $6 \mathrm{~d}$ ), this low energy peak is attributed to arise from absorption from the aggregated species in the polymer film. We refer to the aggregation in chlorobenzene solution in Figure 2c.

High-temperature rubbing experiments were conducted at $230^{\circ} \mathrm{C}$ in order to align the chains. A representative HR-TEM image is shown in Figure 6e. As seen in Figure 6f, the ED pattern of the rubbed films shows a strong 004 reflection at $5.7 \AA$ along the rubbing direction, indicating high alignment of the chains (consistent with the chain periodicity along the backbone direction). Along the equator, the ED pattern shows a strong reflection at 17.4 ̊. Moreover, HR TEM shows clearly a fringed pattern with the same $17.4 \AA$ period. Despite the same inter-chain period of $17.4 \AA$, the rubbed films did not give any evidence for cross-hatched structures as observed in the spincoated films. The contrast in this pattern arises from the density contrast between layers of a-stacked Si-PCPDTBT backbones and layers of alkyl side chains. Si-PCPDTBT chains are well t-stacked and form aligned crystals in face-on orientation in the rubbed films. Interestingly the Si-PCPDTBT do not show a periodic semicrystalline morphology as was found for the rubbed F-PCPDTBT 
samples (compare Figure $5 c+d$ ). Si-PCPDTBT spincoated and drop-cast films consist rather of flake-like or whisker-like domains (see AFM image Figure 6a and Bright Field TEM image in Figure $\mathrm{S} 11 \mathrm{~d}+\mathrm{g}$ ). The absorption spectra are similar for the pi-stacked and the cross-hatched structures, compare Figure 6d.

The rubbed films were further exposed to post-annealing treatment close to the polymer melting point. ED indicates that thermal annealing of the rubbed films at $T=280^{\circ} \mathrm{C}$ results in a change of the crystal orientation from face-on to edge-on with the appearance of the characteristic $3.5 \AA$ [-stacking peak and the fading of the 100 reflection at $17.4 \AA$ (Figure S10i). Therefore, ED does not evidence a change in the polymorphism of Si-PCPDTBT upon thermal annealing but only a reorientation of the crystals. In other words, the -stacked structure in Si-PCPDTBT is thermodynamically stable up to high temperatures close to the polymer melting and does not transform to a dimer-like structure. Linear polarized optical absorption spectroscopy plotted in Figure S2b yielded a moderate dichroic ratio of 2.1, indicating that polymer chain alignment was to some extent successful after rubbing. As a point of reference, using the same rubbing technique on P3HT films, dichroic ratios up to 25 have been observed. ${ }^{48}$ The absorption profile of the thin film after rubbing is plotted in Figure $6 \mathrm{~d}$ and has a $\lambda_{\max }$ at $765 \mathrm{~nm}$, as well as a shoulder around $700 \mathrm{~nm}$. Overall the absorption profile of the face-on, -stacked arrangement is similar to the cross-hatched morphology. 

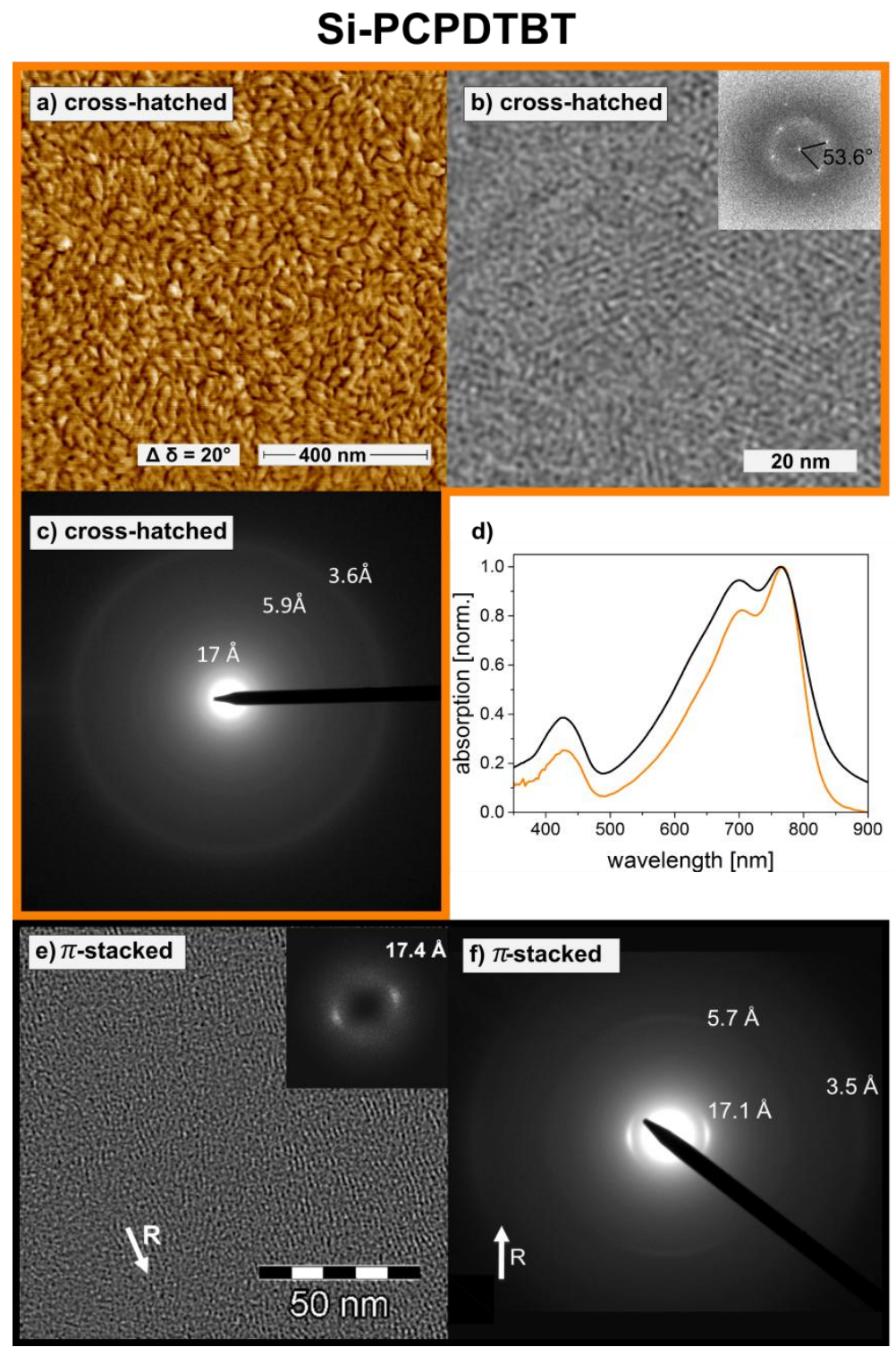

Figure 6. a) AFM phase image of Si-PCPDTBT spincoated from $\mathrm{CB}$ at $80^{\circ} \mathrm{C}$. b) HR-TEM image and c) corresponding ED pattern of spincoated sample. d) Absorption profile of spin coated (orange) and rubbed film (black), respectively. e) HR-TEM image after $\mathrm{HT}$ rubbing at $230^{\circ} \mathrm{C}$. f) ED pattern of Si-PCPDTBT after $\mathrm{HT}$ rubbing at $230^{\circ} \mathrm{C}$. For further morphological data on Si-PCPDTBT we refer to Figures $\mathrm{S} 10+11$.

For the silicon containing analogue, the hole mobility of the predominately cross-hatched oriented morphology (spincoated sample) is compared to that of the mostly face-on oriented pi-stacked chains (HT-rubbing). In both cases, all transistor characteristics were very similar and mobility values between 1 and $2 \times 10^{-2} \mathrm{~cm}^{2} / \mathrm{Vs}$ were equal within the error of the measurement. Although additional thermal annealing at $280^{\circ} \mathrm{C}$ of the mechanically rubbed film led to a clear enhancement of the intensity of the ED reflections, no measurable effect could be seen on the hole mobilities. 
Overall, these findings indicate that there is little effect of the two different packing motifs on the charge transport in FETs for Si-PCPDTBT.

\subsection{Discussion}

Depending on the processing conditions we can access three different polymorphs in the PCPDTBT family. Figure $7 \mathrm{c}, \mathrm{d}$ and e show supercells of the three packing motifs for illustration.

In the case of C-PCPDTBT it is possible to access both an amorphous and stacked film morphology by varying the deposition solvent, whereas for the other two polymers, F-PCPDTBT and Si-PCPDTBT, we could not find the appropriate conditions to make amorphous films. We believe this is due to increased tendency for the polymers to aggregate within the series: C-PCPDTBT, F-PCPDTBT, and Si-PCPDTBT. In fact, the backbone stiffness, evaluated from the scans of the dihedral potentials between the donor and acceptor units of the backbone (Figure S3), was found to be similar for all three polymers, indicating that solvent-polymer interactions play a dominant role in determining polymer film properties.

For all 3 polymers we could access -stacked morphologies. In the case of C-PCPDTBT the addition of diiodooctane to the processing solvent was required, while F-PCPDTBT formed pi-stacked structures upon deposition from CB. Both polymers form edge-on textures on substrates. For Si-PCPDTBT we found -stacked structures upon high temperature rubbing. While mostly face-on textures were observed directly after HT rubbing, additional annealing at $280^{\circ} \mathrm{C}$ lead to mostly edge-on domains. The -stacking distance decreases from $3.75 \AA$, to $3.7 \AA$ to $3.5 \AA$ for C-PCPDTBT, F-PCPDTBT and Si-PCPDTBT. The interlayer spacings are around $17 \AA$ for Si-PCPDTBT and around 11 Å for C- and F-PCPDTBT.

The dimer-like packing motif was exclusively found for F- and C-PCPDTBT. It can be accessed by applying techniques such as high temperature mechanical rubbing, melt-crystallization on friction-transferred PTFE substrates or solvent vapor annealing. The data suggest that this crystal structure is the most thermodynamically stable polymorph for these two polymers.

The silicon containing polymer shows no evidence of dimer-like packing. Even temperature annealing after high temperature rubbing did not lead to the dimer-structures. On the other hand, cross-hatched structures are observed exclusively for Si-PCPDTBT. An interlayer spacing of $17 \AA$ was found in our samples, which is similar to the pi-stacked structures. 
From the standpoint of charge transport, OFET measurements show that the highest charge mobilities are observed for Si-PCPDTBT films with a cross-hatched morphology as compared to the p-stacked and dimer-structures observed for C-PCPDTBT and F-PCPDTBT. Simulations of charge mobilities showed that local ordering tends to favor transport in Si-PCPDTBT as compared to other derivatives. However, the difference in simulated mobilities is smaller than that measured in OFETs, suggesting that large-scale structural and morphological aspects must be considered. In particular, the difference in polymorphism between the analogues must have some impact on charge transport. Our findings open the question on the origin of the polymorphism in this homologous serie of polymers and how this polymorphism affects charge transport. From a molecular point of view, Si-PCPDTBT is clearly distinct from the other two polymers regarding the backbone conformation. Indeed, as seen in Figure $7 a$ and $b$, the backbone conformations of both classes of polymers are clearly distinct regarding the angle phi between the cyclopentadithiophene and the benzodithiazole units. It is equal to $11^{\circ}$ for C-PCPDTBT and F-PCPDTBT versus $19^{\circ}$ for Si-PCPDTBT. Such a difference in phi must impact the packing of the chains and in particular the pi-stacking since the bulky di-ethylhexyl side chains must be accommodated on either side of the layers of that pi-stacked backbones. The higher value of phi for Si-PCPDTBT should translate into a larger layer period as compared to the other analogues. This is indeed observed experimentally: only for Si-PCPDTBT is a large inter-layer period of $17 \AA$ observed versus $11 \AA$ for the other analogues. Moreover, the large enables a new packing of chains into layers in which the directions of the chains make a regular angle in Si-PCPDTBT. Apparently no such cross-hatched chain packing is possible for C-PCPDTBT or F-PCPDTBT because of the smaller value of. Takacs and coworkers suggested that the cross-hatched patterns are due to layers of chains with two in-plane directions making a relative angle of $53^{\circ}$ as shown in Figure $x$. It has been proposed that such cross-hatched domains help interconnect nanocrystals with different in-plane orientations and thus help create quasi-three dimensional transport pathways (2 directions in-plane plus $\pi$-stacking perpendicular to the substrate plane). (refs) The situation is different for both the classical pi-stacked and the dimer polymorphs observed for C-PCPDTBT and F-PCPDTBT. For these systems, charge transport should be essentially $2 \mathrm{D}$ in the $\pi$-stacked crystals and even 1D in the dimer-structure. Macroscopic charge transport in C-PCPDTBT and F-PCPDTBT will imply charges to transit between ordered domains but without the highly interconnected domains found for Si-PCPDTBT. Accordingly, the comparison of charge transport in the analogous serie of PCPDTBTs highlights the essential role of polymorphism that is controlled by a molecular parameter i.e. the Phi angle in the conjugated backbone conformation. 
Such cross-hatched chain arrangements give rise to $2 \mathrm{D}$ charge transport along the two chain directions in the substrate plane. Instead, in a simple -stacked layer in the edge-oirentation, the transport takes place only along the -stacking direction. Accordingly, the dimensionality of charge transport might be strongly influenced by the possibility to build up cross-hatched chain lattices, e.g. by controling the angle in the backbone conformation.

In other words, this is one of the first examples that illustrates how a change in the backbone conformation of a homologous series of polymers results in different packing motives of the chains in a crystal. Moreover, these correlations between backbone structure and packing is observed to coincide correlates with differences in hole mobilities.

(a)

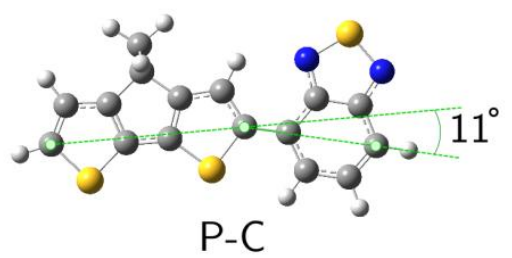

(c)

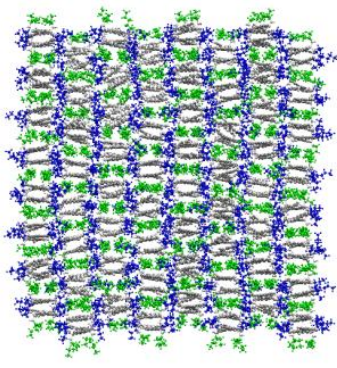

(d)

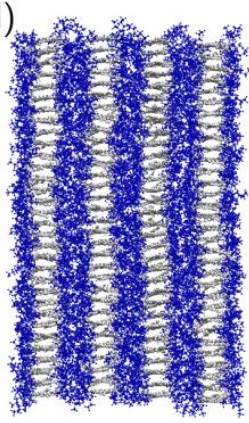

(b)

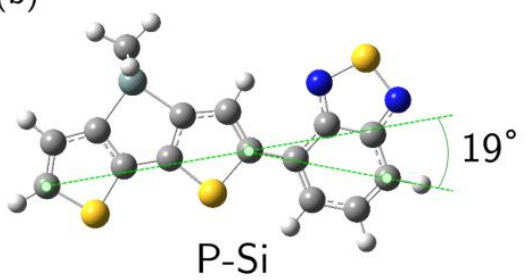

(e)

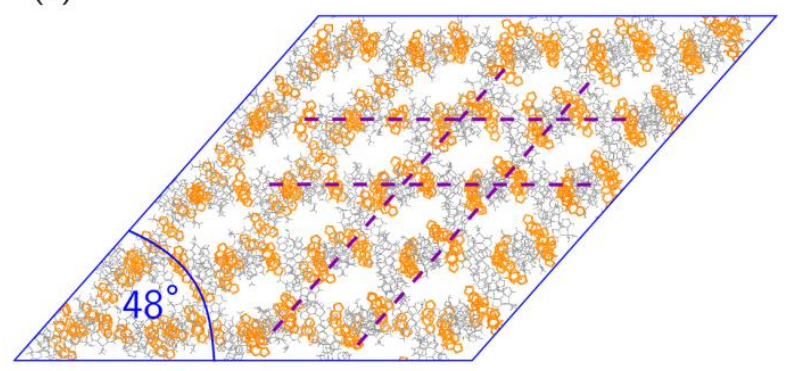

Figure 7. Optimized geometries of one repeat unit for C-PCPDTBT (a) and Si-PCPDTBT (b) highlighting the effect of substituting the bridged carbon atom in the cyclopentadithiophene with silicon. Supercells of the three different packing motifs: dimer (c), -stacked (d) and cross-hatched (e). The cross-hatched morphology was obtained by equilibrating (molecular dynamics, $300 \mathrm{~K}$, NPT ensemble) a supercell ${ }^{53}$ of decamers. 
PCPDTBT-based low bandgap polymers showed the formation of aggregates both in solution and when deposited as thin films. Amorphous, -stacked, cross-hatched, or dimer polymorphs can be obtained by adjusting the processing conditions (nature of solvent, temperature, rubbing, etc). Both experimentally measured and computer simulated hole mobilities confirmed that the stacked Si-PCPDTBT derivative has the highest mobilities in the series. Simulations showed that going from the carbon to the fluorine to the silicon derivative, the local charge mobility of the stacked systems increased. This increase is due to a better registry of the polymer chain backbones and more optimized packing of side chains, which leads to larger effective electronic coupling elements. The dimer-based and the amorphous thin films demonstrated lower mobility values than the -stacked and cross-hatched structures. For the dimer containing morphology, it seems likely that the transport is limited to one direction (along the polymer chain) as the bulky alkyl side chains create a large gap between dimer units. On the whole, small changes in the polymer structure drastically modified aggregation and solubility behavior, thereby strongly influencing the extent of morphology tunability. C-PCPDTBT was the most versatile in the series, next came F-PCPDTBT and finally Si-PCPDTBT. The observed differences in chain packing i.e. dimer-like versus cross-hatched are related, at least in part, to the differences in backbone conformations.

\section{Acknowledgements}

This work was supported in part by the Deutsche Forschungsgemeinschaft (DFG) under the Emmy Noether program, the Priority Program "Elementary Processes of Organic Photovoltaics" (SPP 1355), BMBF grant MESOMERIE (FKZ 13N10723) and MEDOS (FKZ 03EK3503B), and DFG program IRTG 1404 and TRR146. The project has received funding from the NMP-20-2014 "Widening materials models" program under grant agreement No. 646259 (MOSTOPHOS). We are very grateful to $\mathrm{S}$. Janietz who provided us with F-PCPDTBT and H. Klauk, U. Zschieschang, R. di Pietro, and S. Tannert for support with the transistor measurements.

\section{References}

(1) Tremel, K.; Ludwigs, S. Morphology of P3HT in Thin Film in Relation to Optical and Electrical Properties. In P3HT Revisited - From Molecular Scale to Solar Cell Devices; Ludwigs, S., Ed.; Springer: Berlin Heidelberg, 2014; Vol. 265, pp 39-82. 
(2) Sirringhaus, H.; Brown, P. J.; Friend, R. H.; Nielsen, M. M.; Bechgaard, K.; Langeveld-Voss, B. M. W.; Spiering, A. J. H.; Janssen, R. A. J.; Meijer, E. W.; Herwig, P.; et al. Two-Dimensional Charge Transport in Self-Organized, High-Mobility Conjugated Polymers. Nature 1999, 401, 685-688.

(3) Poelking, C.; Daoulas, K.; Troisi, A.; Andrienko, D. Morphology and Charge Transport in P3HT: A Theorist's Perspective. In P3HT Revisited - From Molecular Scale to Solar Cell Devices; Ludwigs, S., Ed.; Springer: Berlin Heidelberg, 2014; Vol. 265, pp 139-180.

(4) Poelking, C.; Andrienko, D. Effect of Polymorphism, Regioregularity and Paracrystallinity on Charge Transport in Poly(3-Hexylthiophene) [P3HT] Nanofibers. Macromolecules 2013, 46, 8941-8956.

(5) Crossland, E. J. W.; Rahimi, K.; Reiter, G.; Steiner, U.; Ludwigs, S. Systematic Control of Nucleation Density in Poly(3-Hexylthiophene) Thin Films. Adv. Funct. Mater. 2011, 21 (3), 518-524.

(6) Crossland, E. J. W.; Tremel, K.; Fischer, F. S. U.; Rahimi, K.; Reiter, G.; Steiner, U.; Ludwigs, S. Anisotropic Charge Transport in Spherulitic poly(3-Hexylthiophene) Films. Adv. Mater. 2012, 24, 839-844.

(7) Leclerc, M. Polyfluorenes: Twenty Years of Progress. J. Polym. Sci. Part A Polym. Chem. 2001, 39, 2867-2873.

(8) Grell, M.; Bradley, D. D. C.; Ungar, G.; Hill, J.; Whitehead, K. S. Interplay of Physical Structure and Photophysics for a Liquid Crystalline Polyfluorene. Macromolecules 1999, 32, 5810-5817.

(9) Brinkmann, M. Directional Epitaxial Crystallization and Tentative Crystal Structure of Poly(9,9'-Di-N-Octyl-2,7-Fluorene). Macromolecules 2007, 40 (21), 7532-7541.

(10) Yan, H.; Chen, Z.; Zheng, Y.; Newman, C.; Quinn, J. R.; Dötz, F.; Kastler, M.; Facchetti, A. A High-Mobility Electron-Transporting Polymer for Printed Transistors. Nature 2009, 457, 679-686.

(11) Kang, H.; Uddin, M. A.; Lee, C.; Kim, K. H.; Nguyen, T. L.; Lee, W.; Li, Y.; Wang, C.; Woo, H. Y.; Kim, B. J. Determining the Role of Polymer Molecular Weight for High-Performance All-Polymer Solar Cells: Its Effect on Polymer Aggregation and Phase Separation. J. Am. Chem. Soc. 2015, 137, 2359-2365.

(12) Tremel, K.; Fischer, F. S. U.; Kayunkid, N.; Di Pietro, R.; Tkachov, R.; Kiriy, A.; Neher, D.; Ludwigs, S.; Brinkmann, M. Charge Transport Anisotropy in Highly Oriented Thin Films of the Acceptor Polymer P(NDI2OD-T2). Adv. Energy Mater. 2014, 4, 1301659.

(13) Brinkmann, M.; Gonthier, E.; Bogen, S.; Tremel, K.; Ludwigs, S.; Hufnagel, M.; Sommer, M. Segregated versus Mixed Interchain Stacking in Highly Oriented Films of Naphthalene Diimide Bithiophene Copolymers. ACS Nano 2012, 6, 10319-10326. 
(14) Mühlbacher, D.; Scharber, M.; Morana, M.; Zhu, Z.; Waller, D.; Gaudiana, R.; Brabec, C. High Photovoltaic Performance of a Low-Bandgap Polymer. Adv. Mater. 2006, 18, 2884-2889.

(15) Peet, J.; Kim, J. Y.; Coates, N. E.; Ma, W. L.; Moses, D.; Heeger, A. J.; Bazan, G. C. Efficiency Enhancement in Low-Bandgap Polymer Solar Cells by Processing with Alkane Dithiols. Nat. Mater. 2007, 6, 497-500.

(16) Peet, J.; Cho, N. S.; Lee, S. K.; Bazan, G. C. Transition from Solution to the Solid State in Polymer Solar Cells Cast from Mixed Solvents. Macromolecules 2008, 41, 8655-8659.

(17) Agostinelli, T.; Ferenczi, T. a. M.; Pires, E.; Foster, S.; Maurano, A.; Müller, C.; Ballantyne, A.; Hampton, M.; Lilliu, S.; Campoy-Quiles, M.; et al. The Role of Alkane Dithiols in Controlling Polymer Crystallization in Small Band Gap polymer:Fullerene Solar Cells. J. Polym. Sci. Part B Polym. Phys. 2011, 49, 717-724.

(18) Rogers, J. T.; Schmidt, K.; Toney, M. F.; Kramer, E. J.; Bazan, G. C. Structural Order in Bulk Heterojunction Films Prepared with Solvent Additives. Adv. Mater. 2011, 23, 2284-2288.

(19) Rogers, J. T.; Schmidt, K.; Toney, M. F.; Bazan, G. C.; Kramer, E. J. Time-Resolved Structural Evolution of Additive-Processed Bulk Heterojunction Solar Cells. J Am Chem Soc 2012, 134, 2884-2887.

(20) Gu, Y.; Wang, C.; Russell, T. P. Multi-Length-Scale Morphologies in PCPDTBT/PCBM Bulk-Heterojunction Solar Cells. Adv. Energy Mater. 2012, 2, 683-690.

(21) Albrecht, S.; Janietz, S.; Schindler, W.; Frisch, J.; Kurpiers, J.; Kniepert, J.; Inal, S.; Pingel, P.; Fostiropoulos, K.; Koch, N.; et al. Fluorinated Copolymer PCPDTBT with Enhanced Open-Circuit Voltage and Reduced Recombination for Highly Efficient Polymer Solar Cells. J. Am. Chem. Soc. 2012, 134, 14932-14944.

(22) Zhang, Y.; Zou, J.; Cheuh, C.; Yip, H.; Jen, A. K.-Y. Significant Improved Performance of Photovoltaic Cells Made from a Partially Fluorinated Cyclopentadithiophene/Benzothiadiazole Conjugated Polymer. Macromolecules 2012, 45, 5427-5435.

(23) Chang, C. Y.; Zuo, L.; Yip, H. L.; Li, Y.; Li, C. Z.; Hsu, C. S.; Cheng, Y. J.; Chen, H.; Jen, A. K. Y. A Versatile Fluoro-Containing Low-Bandgap Polymer for Efficient Semitransparent and Tandem Polymer Solar Cells. Adv. Funct. Mater. 2013, 23, 5084-5090.

(24) Li, Y.; Zou, J.; Yip, H.-L.; Li, C.-Z.; Zhang, Y.; Chueh, C.-C.; Intemann, J.; Xu, Y.; Liang, P.-W.; Chen, Y.; et al. Side-Chain Effect on Cyclopentadithiophene/Fluorobenzothiadiazole-Based Low Band Gap Polymers and Their Applications for Polymer Solar Cells. Macromolecules 2013, 46, 5497-5503. 
(25) Hou, J.; Chen, H.-Y.; Zhang, S.; Li, G.; Yang, Y. Synthesis, Characterization, and Photovoltaic Properties of a Low Band Gap Polymer Based on Silole-Containing Polythiophenes and 2,1,3-Benzothiadiazole. J. Am. Chem. Soc. 2008, 130, 16144-16145.

(26) Morana, M.; Azimi, H.; Dennler, G.; Egelhaaf, H. J.; Scharber, M.; Forberich, K.; Hauch, J.; Gaudiana, R.; Waller, D.; Zhu, Z. H.; et al. Nanomorphology and Charge Generation in Bulk Heterojunctions Based on Low-Bandgap Dithiophene Polymers with Different Bridging Atoms. Adv. Funct. Mater. 2010, 20, 1180-1188.

(27) Albrecht, S.; Vandewal, K.; Tumbleston, J. R.; Fischer, F. S. U.; Douglas, J. D.; Fréchet, J. M. J.; Ludwigs, S.; Ade, H.; Salleo, A.; Neher, D. On the Efficiency of Charge Transfer State Splitting in Polymer:fullerene Solar Cells. Adv. Mater. 2014, 26, 2533-2539.

(28) Chen, H.-Y.; Hou, J.; Hayden, A. E.; Yang, H.; Houk, K. N.; Yang, Y. Silicon Atom Substitution Enhances Interchain Packing in a Thiophene-Based Polymer System. Adv. Mater. 2010, 22, 371-375.

(29) Scharber, M. C.; Koppe, M.; Gao, J.; Cordella, F.; Loi, M. A.; Denk, P.; Morana, M.; Egelhaaf, H.-J.; Forberich, K.; Dennler, G.; et al. Influence of the Bridging Atom on the Performance of a Low-Bandgap Bulk Heterojunction Solar Cell. Adv. Mater. 2010, 22, 367-370.

(30) Scharsich, C.; Fischer, F. S. U.; Wilma, K.; Hildner, R.; Ludwigs, S.; Köhler, A. Revealing Structure Formation in PCPDTBT by Optical Spectroscopy. J. Polym. Sci. Part B Polym. Phys. 2015, 53, 1416-1430.

(31) Fischer, F. S. U.; Tremel, K.; Saur, A.-K.; Link, S.; Kayunkid, N.; Brinkmann, M.; Herrero-Carvajal, D.; Navarrete, J. T. L.; Delgado, M. C. R.; Ludwigs, S. Influence of Processing Solvents on Optical Properties and Morphology of a Semicrystalline Low Bandgap Polymer in the Neutral and Charged States. Macromolecules 2013, 46, 4924-4931.

(32) Fischer, F. S. U.; Trefz, D.; Back, J.; Kayunkid, N.; Tornow, B.; Albrecht, S.; Yager, K. G.; Singh, G.; Karim, A.; Neher, D.; et al. Highly Crystalline Films of PCPDTBT with Branched Side Chains by Solvent Vapor Crystallization: Influence on Opto-Electronic Properties. Adv. Mater. 2015, 27, 1223-1228.

(33) Fischer, F. S. U.; Kayunkid, N.; Trefz, D.; Ludwigs, S.; Brinkmann, M. Structural Models of Poly(cyclopentadithiophene- Alt -Benzothiadiazole) with Branched Side Chains: Impact of a Single Fluorine Atom on the Crystal Structure and Polymorphism of a Conjugated Polymer. Macromolecules 2015, 48, 3974-3982.

(34) Horie, M.; Kettle, J.; Yu, C.-Y.; Majewski, L. A.; Chang, S.-W.; Kirkpatrick, J.; Tuladhar, S. M.; Nelson, J.; Saunders, B. R.; Turner, M. L. Cyclopentadithiophene-Benzothiadiazole Oligomers and Polymers; Synthesis, Characterisation, Field-Effect Transistor and Photovoltaic Characteristics. J. Mater. Chem. 2012, 22, 381-389. 
(35) Kettle, J.; Horie, M.; Majewski, L. A.; Saunders, B. R.; Tuladhar, S.; Nelson, J.; Turner, M. L. Optimisation of PCPDTBT Solar Cells Using Polymer Synthesis with Suzuki Coupling. Sol. Energy Mater. Sol. Cells 2011, 95, 2186-2193.

(36) Baumeier, B.; Kirkpatrick, J.; Andrienko, D. Density-Functional Based Determination of Intermolecular Charge Transfer Properties for Large-Scale Morphologies. Phys. Chem. Chem. Phys. 2010, 12, 11103-11113.

(37) Becke, A. D. Density-Functional Thermochemistry. III. The Role of Exact Exchange. J. Chem. Phys. 1993, 98, 5648.

(38) Marcus, R. A. On the Theory of Oxidation-Reduction Reactions Involving Electron Transfer. I. J. Chem. Phys. 1956, 24, 966.

(39) Rühle, V.; Lukyanov, A.; May, F.; Schrader, M.; Vehoff, T.; Kirkpatrick, J.; Baumeier, B.; Andrienko, D. Microscopic Simulations of Charge Transport in Disordered Organic Semiconductors. J. Chem. Theory Comput. 2011, 7, 3335-3345.

(40) Poelking, C.; Andrienko, D. Long-Range Embedding of Molecular lons and Excitations in a Polarizable Molecular Environment. J. Chem. Theory Comput. 2016, 12, 4516-4523.

(41) Jansen, A. P. J. An Introduction To Monte Carlo Simulations Of Surface Reactions. arXiv 2003.

(42) Guilbert, A. A. Y.; Frost, J. M.; Agostinelli, T.; Pires, E.; Lilliu, S.; Macdonald, J. E.; Nelson, J. Influence of Bridging Atom and Side Chains on the Structure and Crystallinity of Cyclopentadithiophene-Benzothiadiazole Polymers. Chem. Mater. 2014, 26, 1226-1233.

(43) Chang, J. F.; Clark, J.; Zhao, N.; Sirringhaus, H.; Breiby, D. W.; Andreasen, J. W.; Nielsen, M. M.; Giles, M.; Heeney, M.; McCulloch, I. Molecular-Weight Dependence of Interchain Polaron Delocalization and Exciton Bandwidth in High-Mobility Conjugated Polymers. Phys. Rev. B 2006, 74, 115318.

(44) Kline, R. J.; McGehee, M. D.; Kadnikova, E. N.; Liu, J.; Fréchet, J. M. J. Controlling the Field-Effect Mobility of Regioregular Polythiophene by Changing the Molecular Weight. Adv. Mater. 2003, 15, 1519-1522.

(45) Shi, J.; Vincent, C. A. The Effect of Molecular Weight on Cation Mobility in Polymer Electrolytes. Solid State Ionics 1993, 60,11-17.

(46) Goh, C.; Kline, R. J.; McGehee, M. D.; Kadnikova, E. N.; Fréchet, J. M. J. Molecular-Weight-Dependent Mobilities in Regioregular poly(3-Hexyl-Thiophene) Diodes. Appl. Phys. Lett. 2005, 86, 1-3.

(47) Kline, R. J.; McGehee, M. D.; Kadnikova, E. N.; Liu, J.; Fréchet, J. M. J.; Toney, M. F. Dependence of Regioregular Poly(3-Hexylthiophene) Film Morphology and Field-Effect Mobility on Molecular Weight. Macromolecules 2005, 38, 3312-3319. 
(48) Hamidi-Sakr, A.; Biniek, L.; Fall, S.; Brinkmann, M. Precise Control of Lamellar Thickness in Highly Oriented Regioregular Poly(3-Hexylthiophene) Thin Films Prepared by High-Temperature Rubbing: Correlations with Optical Properties and Charge Transport. Adv. Funct. Mater. 2016, 26, 408-420.

(49) Fischer, F. S. U. The Impact of Donor-Acceptor Polymer Crystal Structure and Mesoscopic Morphology on Opto-Electronic Devices, University of Stuttgart, 2015.

(50) Tsao, H. N.; Cho, D. M.; Park, I.; Hansen, M. R.; Mavrinskiy, A.; Yoon, D. Y.; Graf, R.; Pisula, W.; Spiess, H. W.; Müllen, K. Ultrahigh Mobility in Polymer Field-Effect Transistors by Design. J. Am. Chem. Soc. 2011, 133, 2605-2612.

(51) Morana, M.; Wegscheider, M.; Bonanni, A.; Kopidakis, N.; Shaheen, S.; Scharber, M.; Zhu, Z.; Waller, D.; Gaudiana, R.; Brabec, C. J. Bipolar Charge Transport in PCPDTBT-PCBM Bulk-Heterojunctions for Photovoltaic Applications. Adv. Funct. Mater. 2008, 18, 1757-1766.

(52) Martin, D. C.; Thomas, E. L. Grain Boundaries in Extended-Chain Polymers: Theory and Experiment. Philos. Mag. A 1991, 64, 903-922.

(53) Takacs, C. J.; Brady, M. A.; Treat, N. D.; Kramer, E. J.; Chabinyc, M. L. Quadrites and Crossed-Chain Crystal Structures in Polymer Semiconductors. Nano Lett. 2014, 14, 3096-3101.

(54) Pall, S.; Abraham, M. J.; Kutzner, C.; Hess, B.; Lindahl, E. Tackling Exascale Software Challenges in Molecular Dynamics Simulations with GROMACS. In Solving Software challenges for Exascale; Markidis, S., Laure, E., Eds.; Springer: Berlin Heidelberg, 2014; pp 3-27.

(55) Frisch, M. J.; Trucks, G. W.; Schlegel, H. B.; Scuseria, G. E.; Robb, M. A.; Cheeseman, J. R.; Scalmani, G.; Barone, V.; Mennucci, B.; Petersson, G. A.; et al. Gaussian 09. 2009. 


\section{Experimental Section}

\section{Materials.}

Poly[2,6-(4,4-bis(2-ethylhexyl)-4H-cyclopenta[2,1-b;3,4-b']dithiophene)-alt-4,7-(2,1,3-benzothiadi azole)] (PCPDTBT) was purchased from 1-Material. Poly[2,6-(4,4-bis(2-ethylhexyl)-4H-cyclopenta[2,1-b;3,4-b']dithiophene)-alt-4,7-(5-fluoro-2,1,3-be nzothiadiazole)] (F-PCPDTBT) was synthesized by the group of $S$. Janietz at the Fraunhofer Institut für Angewandte Polymerforschung in Potsdam. Poly[(4,4'-bis(2-ethylhexyl)dithiene-[3,2-b:2',3'-d]silole)-alt-4,7-(2,1,3-benzothiadiazole)] (Si-PCPDTBT) was bought from Konarka. All solvents (chlorobenzene, THF, $\mathrm{CHCl}_{3}$, 1,8-diiodooctane, butyl acetate) were purchased from Sigma-Aldrich (p.a. grade). Molecular weights were determined by high temperature gel permeation chromatography in trichlorobenzene at $160^{\circ} \mathrm{C}$ versus polystyrene standards. Absorption solution spectra were measured with a Zeiss spectrometer (light source: CLH600, detector: MCS621 VIS II and MCS611 NIR 2,2 $\mu \mathrm{m}$ ) in transmission mode using fiber optics.

Film processing. As substrates $1 \times 1 \mathrm{~cm}^{2}$ microscope slides (for UV-vis absorption), pure Si-wafers (for AFM), and Si-wafers with a $300 \mathrm{~nm}$ SiOx layer (for TEM) were employed and cleaned with a $\mathrm{CO}_{2}$ snow jet followed by exposure to oxygen plasma (Diener Femto $100 \mathrm{~W}$ ) for at least $600 \mathrm{~s}$. Both, solution and film preparation was done under nitrogen atmosphere. The solvent-additive processed films were prepared from $3 \mathrm{mg} / \mathrm{mL}$ CB solutions in the presence of 2 wt\% DIO, spincoating was performed at $1500 \mathrm{rpm}$ for 300 seconds. The initial films for solvent vapor annealing were prepared from $3 \mathrm{mg} / \mathrm{mL} \mathrm{CHCl}_{3}$ solutions. The films were prepared by spincoating at $1500 \mathrm{rpm}$ for $30 \mathrm{~s}$ within $24 \mathrm{~h}$ after preparation of the solutions. For solvent vapor annealing $\mathrm{CHCl}_{3}$ precast films were exposed to controlled $\mathrm{CS}_{2}$ vapor as previously described. $^{32}$ The films were swollen to a solution like state at a vapor pressure of $92 \%$; recrystallization was induced by decreasing the vapor pressure first to $88 \%$ and then to $85 \%$ within 10 minutes. The temperature of the vapor was set to $22^{\circ} \mathrm{C}$ and the sample temperature to $20^{\circ} \mathrm{C}$. The F-PCPDTBT thin films were deposited from CB solution $(3 \mathrm{mg} / \mathrm{mL})$ and the Si-PCPDTBT films were also made from $3 \mathrm{mg} / \mathrm{mL}$ solutions deposited at $80^{\circ} \mathrm{C}$. High-temperature rubbing of the F-PCPDTBT thin films was performed following a procedure described in the literature. ${ }^{33}$ The rubbing was performed at $240^{\circ} \mathrm{C}$ by applying a rotating cylinder equipped with a fiber cloth with a pressure of 2 bar on the sample holder. 
Film characterization. Oriented areas were identified for transmission electron microscopy (TEM) analysis by optical microscopy (Leica DMR-X microscope). The polymer films were coated with a thin amorphous carbon film and removed from the glass substrates by floating on a diluted aqueous HF solution (5 wt \%) and subsequently recovered on TEM copper grids. Aggregates present in solution were studied by drop-casting CB solutions on TEM copper grids. TEM was performed in bright field, high-resolution and diffraction modes using a CM12 Philips microscope equipped with a MVIII (Soft Imaging System) charge coupled device camera. Calibration of the reticular distances in the ED patterns was made with an oriented PTFE film. UV-vis-NIR spectroscopy was performed with a Zeiss spectrometer (light source: CLH600, detector: MCS621 VIS II and MCS611 NIR 2,2 $\mu \mathrm{m}$ ) in transmission mode using fiber optics. AFM was performed on a Dimension Icon AFM from Bruker operating in tapping mode.

Organic field-effect transistors. Charge transport was probed in organic field-effect transistors in a top-gate bottom-contact geometry in a nitrogen atmosphere. Gold source and drain electrodes of $30 \mathrm{~nm}$ thickness with a $5 \mathrm{~nm}$ thick chromium adhesion layer were evaporated using a shadow mask on glass substrates defining transistor channels with a channel length $(L)$ of 100-250 $\mu \mathrm{m}$ and channel width (W) of $1 \mathrm{~mm}$. The transistor substrates were cleaned by successive ultrasonication in acetone and isopropanol each for $10 \mathrm{~min}$, rinsing in isopropanol and drying in a nitrogen stream. The polymer solution was prepared in the glove box by stirring at elevated temperature for at least $4 \mathrm{~h}$ to allow complete dissolution of the polymer. Polymethylmethacrylate (PMMA) layers (500 nm) (EG-PMMA, Mn $=300 \mathrm{kDa}$, purchased from Polymer Source Inc.) served as dielectric and were spincoated from n-butyl acetate $(60 \mathrm{mg} / \mathrm{mL})$ followed by annealing at $80^{\circ} \mathrm{C}$ for $30 \mathrm{~min}$. In a last step, aluminum (30 nm) was evaporated through a shadow mask and used as gate electrode. Transistor testing was performed with a SUSS Microtech setup connected to a Keithley 2636 Source meter under inert atmosphere. The charge carrier mobilities were extracted from the saturation regime at $-60 \mathrm{~V}$ using, where $\mathrm{I}_{\mathrm{SD}}$ the source-drain current, $C_{i}$ is the capacitance per unit area and $V_{G}$ is the gate voltage. Transfer curves were averaged over all channels lengths $(50,100,150,200 \mu \mathrm{m})$ for 12-16 devices.

Simulation methods. In this paper, MD simulations of C-/F- and Si-PCPDTBT morphologies were performed using the GROMACS simulation package ${ }^{54}$ ( $v$ 4.6.7). Charge transfer integrals, site energies and mobilities were evaluated using a combination of the Gaussian G09 simulation package $^{55}$ and the VOTCA-CTP module ${ }^{39}$. 
For Table of Contents Use

Subtle changes in molecular structure lead to new packing motifs for PCPDTBT polymers.

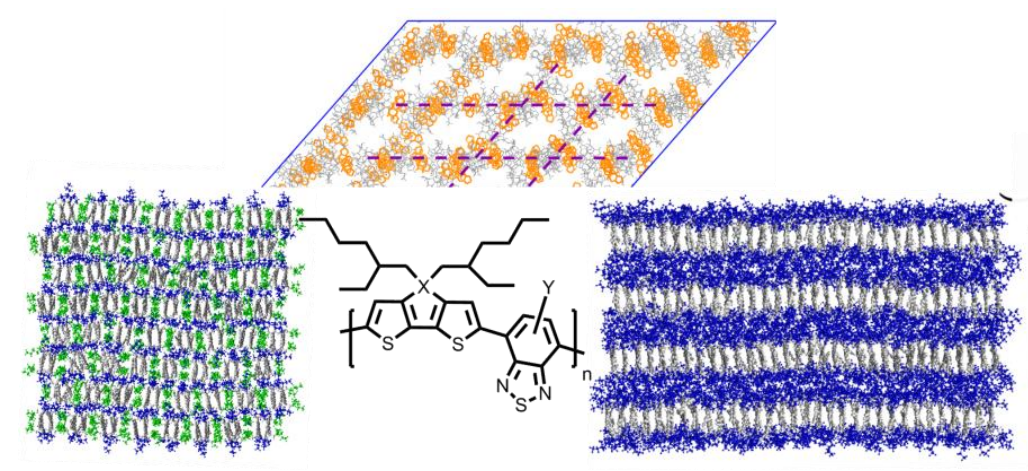

TOC graphic. 